Foster Mieke (Orcid ID: 0000-0002-9832-5350)

Kelly Anne-Maree (Orcid ID: 0000-0002-4655-5023)

Best Guess 2019

How well does the Best Guess method predict children's weight in an

\title{
Emergency Department in 2018-9?
}

\section{Daming PAN}

Medical student, Melbourne Medical School - Western Precinct, The University of Melbourne, St. Albans, Victoria, Australia.

\section{Mieke FOSTER}

Medical Student, Faculty of Medicine, Deakin University

\section{Andrew Tagg MBBS FACEM}

Emergency Physician, Department of Emergency Medicine, Western Health

\section{Sharon KLIM BN}

Joseph Epstein Centre for Emergency Medicine Research @ Western Health, Sunshine, Australia.

\section{Anne-Maree KELLY MD FACEM}

Joseph Epstein Centre for Emergency Medicine Research, Western Health, St Albans,

Victoria, Australia and Department of Medicine, Melbourne Medical School - Western Precinct, The University of Melbourne, St. Albans, Victoria, Australia.

\section{Word count:}

Abstract: 250

Main text: 1844

References: 18

Tables: 3

Figures: 2

Address for correspondence:

This is the author manuscript accepted for publication and has undergone full peer review but has not been through the copyediting, typesetting, pagination and proofreading process, which may lead to differences between this version and the Version of Record. Please cite this article as doi: $10.1111 / 1742-6723.13448$

This article is protected by copyright. All rights reserved. 
Best Guess 2019

\section{Professor Anne-Maree Kelly}

JECEMR, WHCRE

Sunshine Hospital, Furlong Road, St Albans 3021

Email: anne-maree.kelly@wh.org.au

This article is protected by copyright. All rights reserved. 
Best Guess 2019

\section{ABSTRACT}

Objective: For seriously ill children, weight is often required to direct critical interventions. As it is not always feasible to measure weight in emergencies, age-based weight prediction formulae may be used as an alternative. The Best Guess formulae, derived in Australia, have been shown to be among the most accurate age-based methods in Australian children. They were validated in 2010. This study aims to re-validate the Best Guess formulae and compare their performance to the previous validation cohort.

Methods: A prospective observational study was conducted in the paediatric Emergency Department (ED) of a community teaching hospital. It included a convenience sample of children aged 1 month to 10 years who presented between July 2018 and April 2019 . Seriously ill children were excluded. Data collected included measured weight, height, gender, age and ethnic group. The outcomes of interest were predictive performance of Best Guess formulae and comparison of predictive accuracy with a 2005 cohort from the same ED.

Results: 961 patients were included; 42\% girls, median age 3 years. The sample was ethnically diverse. Mean percent difference in weight was $-3.3 \%$ with the formulae usually over-estimating weight. Overall, agreement within $10 \%$ was $41.8 \%$; agreement within $20 \%$ was $72.6 \%$. Predictive accuracy was not significantly different between the cohorts.

Conclusion: The Best Guess method has not reduced in accuracy as a weight estimation method in emergent situations in this Australian cohort, despite a tendency to slightly overestimate children's weight. Further study is needed to test the Best Guess Method's accuracy in ethnic subgroups. 
Best Guess 2019

\section{INTRODUCTION}

For seriously ill children, medication doses and other critical interventions are usually weightbased. As it is not always feasible to measure weight in an emergency, age-based weight prediction formulae may be used as an alternative. Commonly used age-based formulae include the Advanced Paediatric Life Support (APLS) formula (both original and 2011 updated versions), the Luscombe formula, the Argall formula and the Best Guess formulae.

The Best Guess formulae were derived in Australia [1] and in validation have been shown to be among the most accurate age-based methods.[2,3] They were last validated in 2010.[4]

The Best Guess method is actually three separate formulae estimating children's weight for different age groups.

- $\quad$ For children who are less than 12 months old - weight $=[($ age in months +9$) / 2]$

- $\quad$ For children between 1 and 4 years old - weight $=[2 \times($ age in years $)+4]$

- $\quad$ For children between 5 and 14 years old - weight $=(4 \times$ age in years $)$

There is evidence that children's weight and the prevalence of obesity in children is increasing.[5,6] This could challenge the predictive accuracy of age-based formulae, including the Best Guess formulae. We chose to re-validate the Best Guess formulae because they were derived from Australian data and so are more likely to be applicable to Australian children. There is evidence that age-based formulae perform less well in populations different from those in which they were derived.[7,8] They have also been consistently among the most accurate age-based formulae in Australian populations.[2-4] 
Best Guess 2019

The objectives of this study were:

1. To determine the predictive accuracy of the Best Guess weight estimation formulae in a 2018-9 cohort of children; and

2. To compare its current predictive accuracy to 2005 data from the same ED that was used in its original validation.

\section{METHODS}

This was a prospective observational cohort study conducted in the Emergency Department (ED) of Sunshine Hospital, a mixed adult-paediatric ED in Melbourne with an annual paediatric census of about 25,000 .

Participants were a convenience sample of children aged 1 month-10 years who presented to the ED between July 2018 and April 2019. Sampling was based on the availability of data collectors (DP and MF). Children triaged as high acuity (Australasian Triage Scale categories 1 and 2) or declining consent were excluded. Verbal consent was obtained for participation and children were excluded if they or their parents declined.

Data were collected directly from patients or their parents. They were approached in either waiting room or in ED treatment areas after they had been triaged. They were provided with a brief explanation of the project and verbal consent was obtained. Non-identifiable data was recorded on a piloted data sheet and then transferred into an Excel spreadsheet with password protection. Data included:

- Age, for children aged $<1$ year in months and for those aged $>1$ year age at last birthday

- Gender 
Best Guess 2019

- Patient's weight in kilograms to one decimal place. For patients aged above one year old, weight was measured on calibrated scales without shoes and heavy layers of clothing, either standing (Seca ${ }^{\mathrm{TM}}$ electronic scale) or sitting (Healthometer ${ }^{\mathrm{TM}}$ electronic scale). For infants below one year old, their bare weights were measured on a baby weight scale. Scales were calibrated by the Sunshine Hospital biomedical department before the start of the project, monthly during the study and at the study conclusion. If a child was not able to sit or stand still on the scale, the weight of the parent/carer was measured both with and without holding the child with the child's weight being the difference between the two measurements.

- Patient's height in centimeters to one decimal place. For patients who are able to stand, height was measured with a stadiometer without shoes. For infants who could not stand or were less than one meter tall, length was measured with a Seca ${ }^{\text {тм }} 207$ infant measurement rod in the supine position.

- Self-identified ethnicity as reported by the parent or carer and classified as one of: Caucasian, Asian, Indian/Sri Lankan, African, Polynesian/Pacific Islander and other. These categories reflect the known common ethnic groups in the ED's catchment area.

- BMI-for-age percentiles were calculated using the Center for Disease Control (CDC) charts.[9] As per CDC defintions, underweight was defined $a s<5^{\text {th }}$ percentile BMI for age and gender. Normal weight was defined as 5th percentile to less than the 85th percentile BMI. Obese was defined as $85^{\text {th }}-94^{\text {th }}$ percentile $\mathrm{BMI}$ and obese as $\geq 95^{\text {th }}$ percentile BMI

The primary outcomes of interest were: 
Best Guess 2019

- Predictive accuracy of the Best Guess formulae as assessed by mean percent difference, agreement within $10 \%$ of measured weight and agreement within $20 \%$ of measured weight; and

- Comparison of the accuracy as assessed by mean percent difference, agreement within $10 \%$ of measured weight and agreement within $20 \%$ of measured weight between data collected for this study and data collected for a paediatric weight estimation study at the same ED in 2005.

Secondary outcomes were subgroup analysis by gender, ethnicity and age group.

Data are presented as descriptive statistics (median, interquartile range (IQR) and proportions) for gender, age, weight, height, ethnicity, BMI, mean percent difference and agreement within $10 \%$ and $20 \%$ of measured weight. Analysis was performed using Analyse-IT for Microsoft Excel $^{\mathrm{TM}}$, Leeds, UK.[10] Comparison between this cohort and the 2005 cohort was performed using Chi Square test (2x2 or omnibus) for categorical variables and Mann Whitney $U$ Test for continuous variables using Analyse IT for Microsoft Excel ${ }^{\mathrm{TM}}$, Leeds, UK.[10]

Regarding sample size, this was a time-limited student project which influenced the amount of data that could be collected. Formal sample size estimation was not performed. We aimed to collect data from a minimum of 800 patients which would be sufficient to identify a $10 \%$ difference in the proportion of patients with estimated weight within $10 \%$ of measured weight with power of 0.8 and alpha of 0.05 between the two time periods.

This project was approved by the Western Health Low Risk Ethics Panel (QA2018.61). 
Best Guess 2019

\section{RESULTS}

A total of 981 children were recruited of whom 20 were excluded because they were aged $\geq$ 11 years, resulting in a sample of analysis of 961 . Characteristics of the sample are shown in Table 1 . There are more boys (58\%) than girls in the sample, and the median age was 3 years (95\% Cl 1-6). Half (50.5\%) of the sample are Caucasian children and $20.5 \%$ patients are Asian.

Predictive performance of the Best Guess method is shown in Table 2. Overall, the Best Guess method had a mean percent difference of $-3.3 \%(95 \% \mathrm{Cl}:-4.54$ to $-2.07 \%)$. This indicates that the method slightly over-estimated measured weight. The majority (72.6\%) of the sample are within $20 \%$ agreement of the actual weight and $41.8 \%$ of total are within $10 \%$ agreement of the measured weight. Distribution of the percent difference between estimated and measured weight is shown in Figure 1. Agreement within $10 \%$ and $20 \%$ for the group overall and for age, BMI-for age, gender and ethnicity subgroups are shown in Figure 2.

Comparison of the Best Guess methods' predictive performance between this cohort and the 2005 cohort is shown in Table 3. As the 2005 cohort did not recruit children under one year old, data of 2018-9 cohort in table 3 excludes children age from 1 to 12 months. The two samples have a similar age and gender distribution. There is a significant change in the ethnic mix of the samples. The proportion of Caucasian children was $74.9 \%$ in 2005 cohort and $50.6 \%$ in 2018-9 cohort. Difference of predictive performances of Best Guess formulae between both cohorts are not statistically significant for mean difference, agreement within $10 \%$ of measured weight and agreement within $20 \%$ of measured weight. 
Best Guess 2019

\section{DISCUSSION}

Age-based formulae can be used to estimate children's weight in emergencies where direct measurement is not feasible. While a number of formulae have been proposed, the Best Guess method has shown to be among the most accurate in Australian childen.[2-4] Performance within other populations has been variable.[4,5,11] The method was developed in the 2000's and last validated in 2010 .

There is evidence that the proportion of children who are overweight or obese is increasing. Australian data suggests that the proportion of children overweight or obese had increased from $24.7 \%$ to $27.6 \%$ between 1995 and 2014/5.[5]. Globally, in developing countries, the prevalence of overweight or obesity in children has increased from $16.9 \%$ to $23.8 \%$ for boys and $16.2 \%$ to $22.6 \%$ for girls between 1980 and 2013.[6] There was concern that with the increasing weight of children, the predictive accuracy of the Best Guess method might have been significantly compromised.

Our results show that the Best Guess method has not reduced in accuracy. The 2018-9 result did not show a statistically significant difference compared to 2005 data regarding percentage difference in weight or agreement within $10 \%$ and $20 \%$ of the actual weight.

Age-based methods have been criticized as being the least accurate of the available weight estimation methods.[11] Simple observation informs us that children of the same age vary significantly in size.[12] An alternative to age-based weight estimation methods is anthropometry-based methods. These include the Broselow tape,[13] Pediatric Advanced Weight-Prediction in the Emergency Room (PAWPER) tape [14] and the Mercy Method.[15] 
Best Guess 2019

These methods may be particularly useful where data regarding age is unavailable/inaccurate. They do however have the weakness that they cannot be used until the child is present.[12] This does not facilitate preparation before a critically ill child arrives. Age-based formulae do not have this limitation.

An alternative to estimating a child's weight is to ask parents to estimate. Studies have shown that $75-78 \%$ of estimates are within $10 \%$ of measured weight and $92 \%$ agreement within $20 \%$ of measured weight.[16,17] Alternative methods are required for the approximately $10 \%$ of case where parents are unwilling to give an estimate. To date, no studies have evaluated the use, accuracy or availability of parental estimates in critically ill children.

There no agreement target or benchmark about what constitutes acceptable parameters of weight estimation. A target of $70 \%$ of estimates within $10 \%$ of measured weight and $95 \%$ within $20 \%$ of measured weight has been suggested $[11,18]$, but is probably unrealistic given the variation in children's size and growth patterns by age. Perhaps an agreement level of $75-80 \%$ of estimates within $20 \%$ of measured weight is more realistic.

It is interesting that the Best Guess method has maintained its performance despite a significant change in the ethnic make-up of the study sample. That said, because of small sample sizes in some ethic subgroups, we are not able to rule out the possibility that the pooling of results masks poorer performance in some of these groups.

This study has a number of limitations that should be considered when interpreting our results. Data was collected from a single centre and the results may not be generalizable to other 
Best Guess 2019

centres. The study was based on a convenience sample of patients with enrolment dependent on the availability of researchers. This resulted in data collection mainly being done in weekday day shifts which may have introduced bias. We believe this is unlikely due to the large sample size. Additionally, higher acuity children were excluded.

\section{CONCLUSION}

The Best Guess method has maintained its accuracy as a weight estimating method in emergent situations in this Australian cohort, albeit with a tendency to slightly over-estimate children's weight. Further study is needed to test the Best Guess Method's accuracy in ethnic sub-groups.

\section{REFERENCES}

1. Tinning K, Acworth J. Make your Best Guess: an updated method for paediatric weight estimation in emergencies. Emerg Med Australas. 2007;19:528-34.

2. Thompson MT, Reading MJ, Acworth JP. Best Guess method for age-based weight estimation in paediatric emergencies: validation and comparison with current methods. Emerg Med Australas. 2007;19:535-42.

3. Kelly AM, Kerr D, Clooney M, Krieser D, Nguyen K. External validation of the Best Guess formulae for paediatric weight estimation. Emerg Med Australas. 2007;19:543-6.

4. Casey J, Borland M. Best Guess method: a further external validation study and comparison with other methods. Emerg Med Australas. 2010;22:68-74.

5. Huse O, Hettiarachchi J, Gearon E, Nichols M, Allender S, Peeters A. Obesity in Australia. Obes Res Clin Pract 2018;12:29-39. 
Best Guess 2019

6. Ng M, Fleming T, Robinson M, Tomson B, Graetz N, Margono C et al. Global, regional, and national prevalence of overweight and obesity in children and adults during 1980-2013: a systematic analysis for the Global Burden of Disease Study 2013. Lancet 2014;384(9945):766-81.

7. Batmanabane G, Jena PK, Dikshit R, Abdel-Rahman S. Using the Mercy Method for Weight Estimation in Indian Children. Glob Pediatr Health. 2015; 2:2333794X14566625.

8. Geduld H, Hodkinson PW, Wallis LA. Validation of weight estimation by age and length based methods in the Western Cape, South Africa population. Emerg Med J . 2011; 28:856-60.

9. https://www.cdc.gov/growthcharts/clinical charts.htm. Accssed October 2018.5.

10. Analyse-It. https://analyse-it.com/ Leeds, UK

11. Wells M, Goldstein LN, Allison B. It is time to abandon age-based emergency weight estimation in children! A failed validation of 20 different age-based formulas. Resuscitation 2017; 116: 73-83.

12. https://www.stemlynsblog.org/apls-estimation-formulas-do-not-safely-predict-weight-in-ukchildren-st-emlyns/. Accessed 8 October 2019

13. Wells M, Goldstein LN, Bentley A, Basnett S, Monteith I. The accuracy of the Broselow tape as a weight estimation tool and a drug-dosing guide - A systematic review and metaanalysis. Resuscitation 2017;121:9-33.

14. Wells M, Goldstein LN, Bentley A. Development and validation of a method to estimate body weight in critically ill children using length and mid-arm circumference measurements: The PAWPER XL-MAC system. S Afr Med J 2017;107:1015-1021. 
Best Guess 2019

15. Batmanabane G, Jena PK, Dikshit R, Abdel-Rahman S. Using the Mercy Method for Weight Estimation In Indian Children. Glob Pediatr Health 2015: 2:2333794X14566625.

16. Krieser D, Nguyen K, Kerr D, Jolley D, Clooney M, Kelly AM. Parental weight estimation of their child's weight is more accurate than other weight estimation methods for determining children's weight in an emergency department? Emerg Med J. 2007;24:756-9.

17. Foster M, Tagg A, Klim S, Kelly AM. Accuracy of parental estimate of child's weight in a paediatric emergency department. Emerg Med Australas. 2019 May 30. [epub ahead of print] 18. Stewart D. Accuracy of the Broselow tape for estimating paediatric weight in two Australian Emergency Departments. University of Sydney; 2009. 
Best Guess 2019

Table 1. Patient characteristics

\begin{tabular}{|c|c|c|c|}
\hline Variable & Description & Result & Missing data \\
\hline Age & Median, IQR & $3 ; 1-6$ & \\
\hline \multirow{3}{*}{$\begin{array}{l}\text { Age group (years, } \\
\mathrm{N}, \%)\end{array}$} & $<1$ & $142 ; 14.8 \%$ & \\
\hline & $1-4$ & $477 ; 49.6 \%$ & \\
\hline & $5-10$ & $342 ; 35.6 \%$ & \\
\hline Gender & Male, N, \% & $553 / 953,58 \%$ & 8 \\
\hline \multirow[t]{6}{*}{ Ethnicity } & Caucasian/European & $475 ; 50.5 \%$ & 20 \\
\hline & Asian & $193 ; 20.5 \%$ & \\
\hline & Indian/ Sri Lankan & 130: $13.8 \%$ & \\
\hline & African & $73 ; 7.8 \%$ & \\
\hline & $\begin{array}{l}\text { Polynesian/ Pacific } \\
\text { Islander }\end{array}$ & $46 ; 4.7 \%$ & \\
\hline & Other & $24 ; 2.6 \%$ & \\
\hline \multirow[t]{5}{*}{ BMI for age $(n=509) \#$} & & & 123 \\
\hline & Underweight & $56,11 \%$ & 123 \\
\hline & Healthy weight & $326,64 \%$ & \\
\hline & Overweight & $60,11.8 \%$ & \\
\hline & Obese & $67,13.2 \%$ & \\
\hline \multicolumn{4}{|l|}{ Median weight (IQR) } \\
\hline & $<1$ & 7.8 kg (6.1-9.7) & \\
\hline & $1-4$ & $14 \mathrm{~kg}(11.5-16.3)$ & \\
\hline & $5-10$ & $26.5 \mathrm{~kg}(21.5-33)$ & \\
\hline
\end{tabular}

\# BMI - body mass index, can only be calculated for children aged $\geq 2$ 
Best Guess 2019

Table 2. Predictive performance of Best Guess method Results 2018-9 cohort

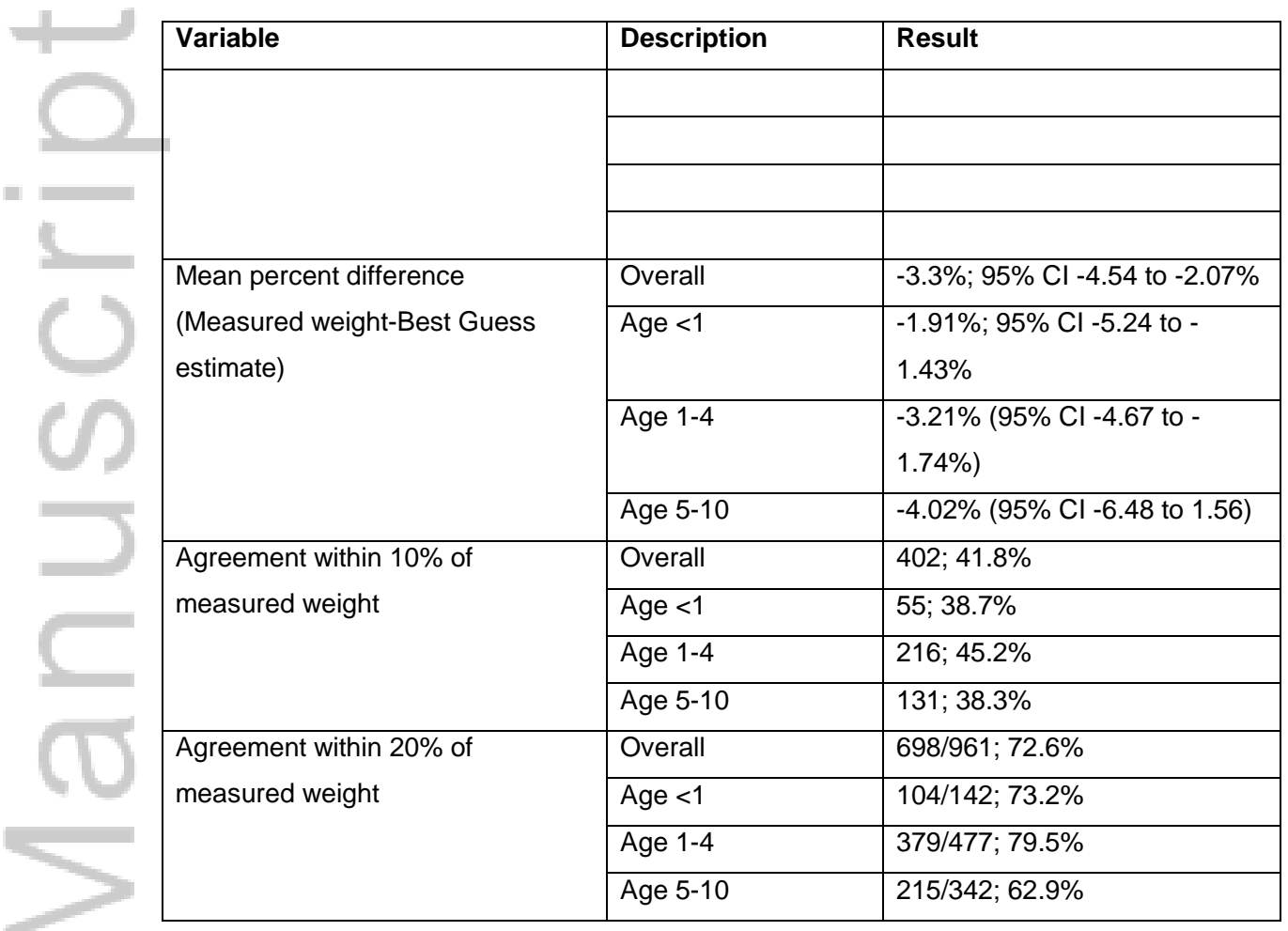

This article is protected by copyright. All rights reserved. 
Best Guess 2019

Table 3. Comparison of the Best Guess method's predictive performance between 2018-9 and 2005 cohort

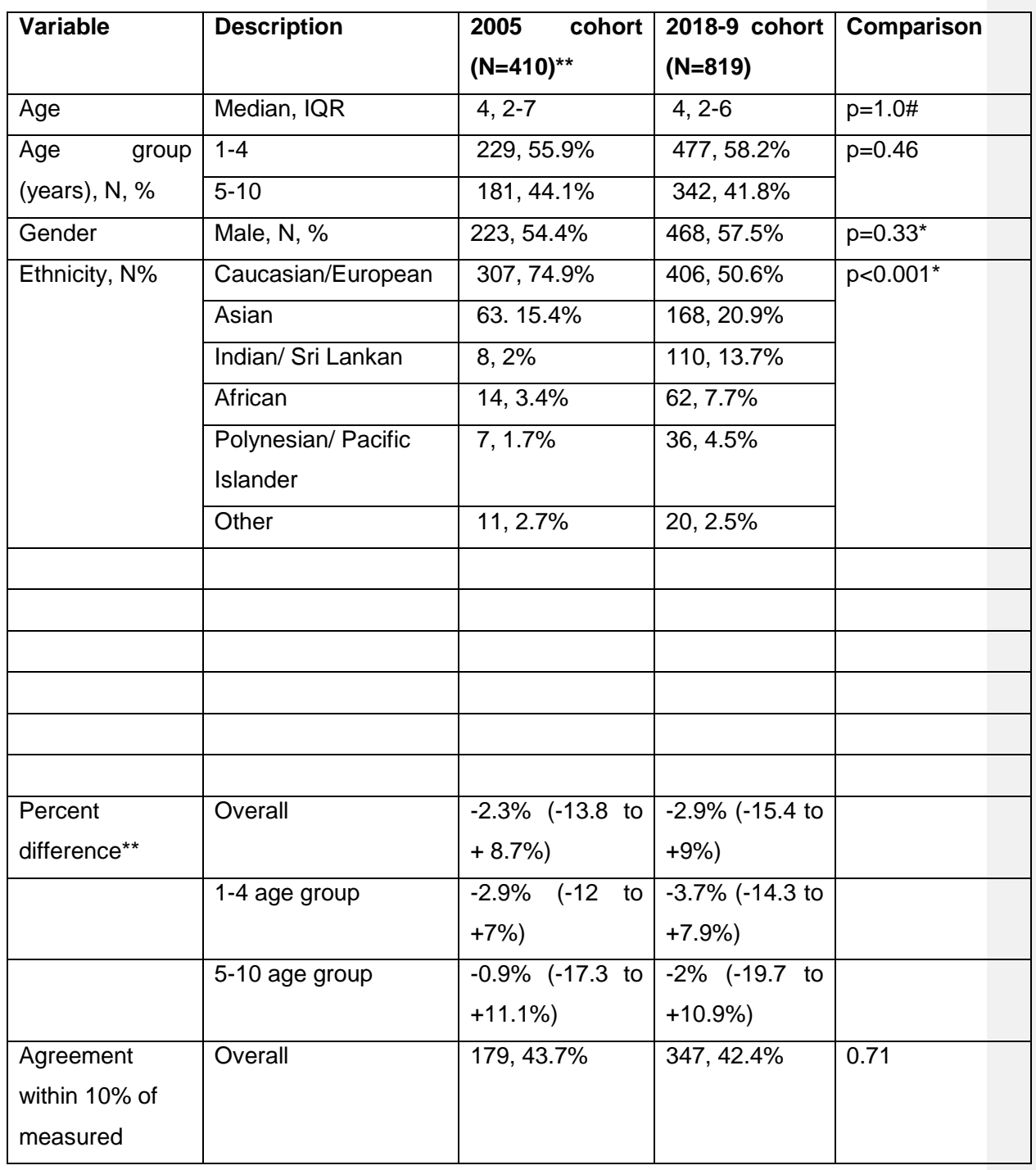

This article is protected by copyright. All rights reserved. 
Best Guess 2019

\begin{tabular}{|l|l|l|l|l|}
\hline weight (N, \%) & & & & \\
\hline & $1-4$ age group & $113.49 .3 \%$ & $216,45.3 \%$ & 0.35 \\
\hline $\begin{array}{l}\text { Agreement } \\
\text { within 20\% of } \\
\begin{array}{l}\text { measured } \\
\text { weight (N, \%) }\end{array}\end{array}$ & Overall & $66,36.5 \%$ & $131,38.3 \%$ & 0.75 \\
\hline & $1-4$ age group & $195,85.2 \%$ & $379,79.5 \%$ & 0.1 \\
\hline
\end{tabular}

\#\# Measured weight - formula estimate;

** (Measured weight - formula estimate/ measured weight)

*100; \# Mann Whitney U test, two-sided,

*Chi Squared/ Omnibus Chi Squared test

** 2005 cohort did not include children $<1$. 


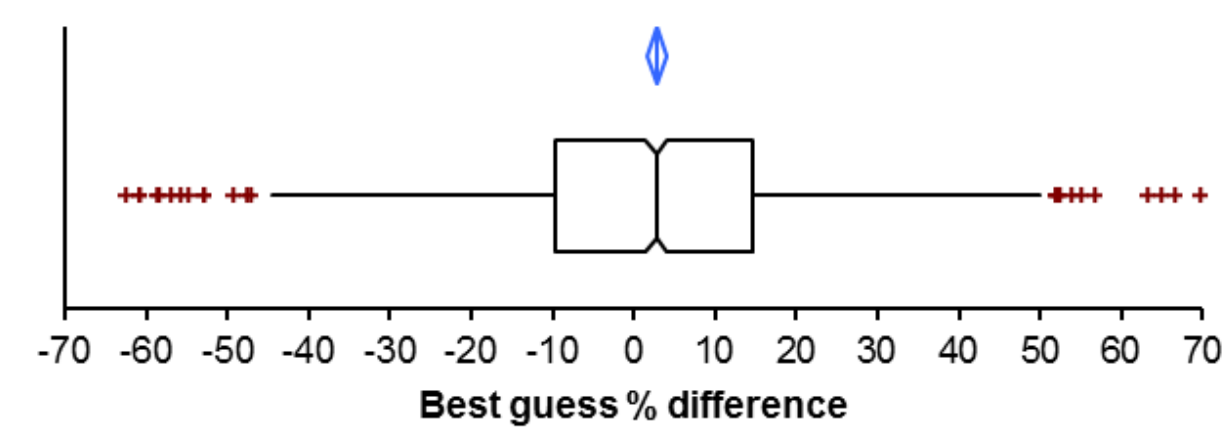

95\% CI Notched Outlier Boxplot Median (2.9)

95\% CI Mean Diamond Mean (2.7)

+ Outliers $>1.5$ and $<3$ IQR

This article is protected by copyright. All rights reserved. 


\section{University Library}

\section{- M M N E R VA A gateway to Melbourne's research publications}

Minerva Access is the Institutional Repository of The University of Melbourne

Author/s:

Pan, D;Foster, M;Tagg, A;Klim, S;Kelly, A-M

Title:

How well does the Best Guess method predict children's weight in an emergency department in 2018-2019?

Date:

2019-12-19

Citation:

Pan, D., Foster, M., Tagg, A., Klim, S. \& Kelly, A. -M. (2019). How well does the Best Guess method predict children's weight in an emergency department in 2018-2019?. EMERGENCY MEDICINE AUSTRALASIA, 32 (1), pp.135-140. https://doi.org/10.1111/1742-6723.13448.

Persistent Link:

http://hdl.handle.net/11343/286764 